\title{
Extreme Temperature Range Microelectronics
}

\author{
DAVID W. PALMER AND RICHARD C. HECKMAN
}

\begin{abstract}
Down-hole geothermal instrumentation must operate over a large temperature range. The technology and capabilities of room temperature to $300^{\circ} \mathrm{C}$ hybrid and printed-circuit (PC) board electronics that were developed during the last two years to meet that need are summarized. To ensure rapid widespread commercialization, this technology was developed, insofar as possible, using commerically available components, devices, and materials. Initial extensive high-temperature characterization revealed that selected thickfilm passive components and silicon junction-fieldeffect transistors had electrical parameters sufficiently insensitive to temperature change and sufficiently constant in time at high temperatures to form the backbone of this circuitry. Attachment techniques needed to be developed, since standard methods failed at high temperatures. Similarly, circuit design innovations were needed because of the restricted list of parts. Voltage regulators, line drivers, voltage comparators, special purpose amplifiers and multiplexers were constructed and operated over the $25-300^{\circ} \mathrm{C}$ temperature range. Temperature and pressure monitoring instruments using these circuits have been used for downhole measurements in geothermal wells. Methods of fabrication, circuit performance, and the scope of future work are discussed.
\end{abstract}

\section{INTRODUCTION}

O USE geothermal fluids for the generation of electricity with reasonable efficiency, a temperature of at least $150^{\circ} \mathrm{C}$ is needed [1], [2]. In fact, most geothermal reservoirs in use or being investigated have down-hole temperatures from $250-370^{\circ} \mathrm{C}$, which is considerably above standard operating temperatures for electronics. To justify the expense of a well-top generating station, accurate estimates of reservoir potential must be made, and these are based in part on downhole measurements.

As a step in meeting the needs for down-hole geothermal instrumentation, a microcircuit technology was developed. These circuits have been operated from $25-300^{\circ} \mathrm{C} .{ }^{1}$ Commercial materials, components, and devices were used with a few exceptions so that the technology is readily available to the logging (down-hole measurement) industry. To achieve both $300^{\circ} \mathrm{C}$ operation and commercial availability within a short development time, some compromises with typical fabrication methods have been made. For example, high-temperature prescreening and characterization of crucial components and devices are necessary. Each instrument must be individually calibrated through the complete temperature range, and circuit lifetimes at maximum operating temperatures of a few hundred hours are accepted.

Manuscript received April 26, 1978; revised July 13, 1978. This work was supported by the U.S. Department of Energy.

The authors are with Sandia Laboratories, Albuquerque, NM 87115.

$125-300^{\circ} \mathrm{C}$ is the operational range needed within the geothermal well. This temperature range could be extended to at least $-55^{\circ} \mathrm{C}$ on the low end with no technology change. However, this would only make calibration and alignment more tedious while gaining little in field performance.
The most surprising aspects of this research are, first, that successful operation of circuits is possible using only selected or slightly modified commercial parts and materials and, second, that there is a broad-based interest in using hightemperature electronics. For example, engineers developing electronic monitors for jet engines, deep gas wells, turbines, automobile engines, and nuclear power plants have indicated a strong interest in electronics which operate to $300^{\circ} \mathrm{C}$.

The lure of high-temperature electronics is not new, but the field has not heretofore had a single driving force of sufficient duration and magnitude to support establishment of a lasting technology. In the late 1950's, the prospect of satellite and reentry vehicle environments produced a burst of work in a high-temperature components (See, for example, [3] ). However, improvements in insulation and radiator design soon preempted this need, and the technology did not mature. Similarly, long-standing requirements for jet engine or nuclear reactor monitoring have thus far been met using either high-temperature transducers with long cables or by cooling instrument packages, rather than with electronics capable of severe environments.

The advent of a federally sponsored program for the stimulation of geothermal energy use has again prompted the development of a high-temperature electronics technology. It is the purpose of this paper to review developments in this area. Brief discussions are given of passive and active components, packaging, interconnections, and magnetic materials. Next, some circuit technology is discussed. Lastly, some comments are included giving one view of the near-term direction of the field. The material discussed in detail previously in the literature will be reviewed only briefly here.

\section{MATERIALS AND DEVICES}

\section{A. Passive Components}

The approach to developing this high-temperature electronics has emphasized thick-filmed hybrid technology [4], [5]. With this method, adequate miniaturization is obtained for current logging needs, and because the technology is intrinsically refractory, it promises successful high-temperature operation.

Fritless conductor materials are used to eliminate surface layers that would interfere with bonded interconnections. Typically, the conductors are gold-based materials to insure bond capatibility with gold beam-lead devices, gold ribbons, and gold-coated diffusion-barrier pads. To ameliorate the effects of interdiffusion between aluminum bond wire and the conductor, the gold containing inks were slightly modified with additives by the manufacturers. The substrates were $96 \%$ alumina. 
Most of the standard thick-film resistor compositions that were initially studied displayed resistance changes of about $5 \%$ from room temperatures to $300^{\circ} \mathrm{C}$. Changes of $1 \%$ or less are desirable for many circuits. By appropriate additions of rhodium oxides, which contribute a negative temperature coefficient of resistance, Cermalloy was able to produce an ink having a minimum in the temperature coefficient of resistance (TCR) at $150^{\circ} \mathrm{C}$ and a change of less than $0.3 \%$ over the desired temperature range (Cermalloy series 530, lot 2430). Further measurements have indicated two other materials with small net resistance changes: DuPont 1500 series ( $\sim 1 \%)$ and Thick-Film Systems 850 $(\sim 2 \%)$. (See Fig. 1.) All thick-film resistors tested show little drift $(<1 \%)$ with time at $300^{\circ} \mathrm{C}$ after an initial 100 -hour burn-in. Several versions of chip thick-film resistors from Caddock likewise had low TCR and were stable. These resistors were tested to $500^{\circ} \mathrm{C}$ which suggests that thick-film circuitry for this temperature may be achievable. Caddock does not market the unfired thick-film ink.

A component still being developed is a sliding contact thick-film potentiometer that is intended to replace wirewound potentiometers in a pressure guage and a caliper tool. Tests are being conducted with the DuPont 1500 resistor series inks and Paliney 7 contact material. This thick-film system should have higher resolution and allow higher temperature operation. An additional application for this potentiometer is in trimpots.

Thermistors are important in designing circuits that operate over wide temperature ranges. These thermistors might typically be placed in series with diodes or transistors to compensate for impedance changes. Thick-film thermistor inks are available with positive and negative TCR's and both linear and exponential (negative only) dependences ( \pm 100 to 10000 parts per million (ppm) $/{ }^{\circ} \mathrm{C}$ ). Thick-Film Systems $850 \mathrm{~N}$, $P$ series, and EMCA Firon TM 100 and 5000 series have been tested and were found to be linear or exponential over the entire $25-300^{\circ} \mathrm{C}$ range and stable with time.

Capacitors are more complex in their behavior than resistors. Most multilayer ceramic-brick capacitors tested displayed excessive leakage, and their dielectric properties were unstable above $225^{\circ} \mathrm{C}$. Solid-tantalum capacitors showed slow but steady irreversible aging above $250^{\circ} \mathrm{C}$. For large low-voltage power-supply filter capacitors, solidaluminum electrolytics were found adequate [6]. For values up to $4000 \mathrm{pF}$, thick-film monolayer capacitors were found to be extremely stable to $300^{\circ} \mathrm{C}$ (less than $1 \%$ change in capacitance with temperature and time), although they require substantial substrate area $\left(250 \mathrm{pF} / \mathrm{cm}^{2}\right)$. At $300^{\circ} \mathrm{C}$ and 1000 $\mathrm{Hz}$ a typical dissipation factor is $2 \%$ and the insulation resistance for low voltage is at least $2 \mathrm{M} \Omega-\mu \mathrm{F}$. The capacitors are fabricated by consecutively cross printing and firing two dielectric layers to avoid pinholes and thus to enhance the yield. Three dielectric materials have been predominantly used to date: DuPont 8299, which is fired below its recrystallization temperature; ESL 4301, which is excellent up to $300^{\circ} \mathrm{C}$; and TFS 1005 , with a slightly lower dielectric constant and good to $350^{\circ} \mathrm{C}$. For larger capacitances $(10000-$ $20000 \mathrm{pF}$ ), ESL 4515 has been used successfully (see Fig. 2 ). The change in capacitance over the complete tempera-

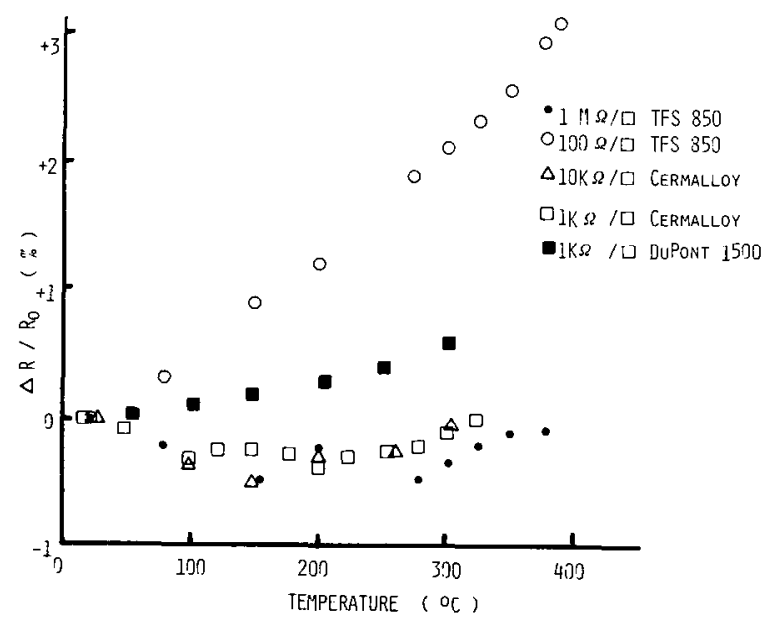

Fig. 1. Resistance change with temperature of some low TCR inks. Cermalloys 500 scries inks have been modified for minimum resistance near $150^{\circ} \mathrm{C}$ rather than $25^{\circ} \mathrm{C}$.

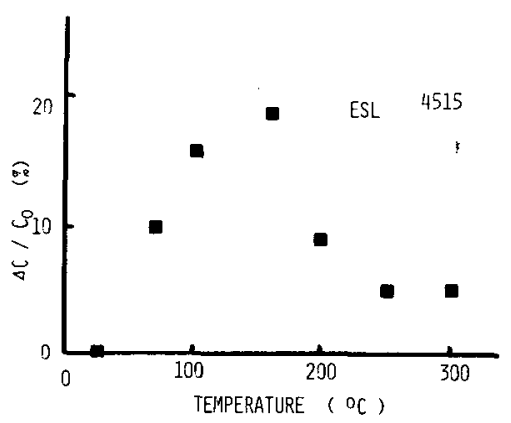

Fig. 2. Change in capacitance with temperature of ESL 4515 dielectric composition. Capacitor was $4 \mathrm{~cm}^{2}$ in area with $10000 \mathrm{pF}$ capacitance. Dissipation factor over temperature range was 3\% $(1000 \mathrm{~Hz})$.

ture range can be $10-20 \%$, but for many applications this is acceptable.

\section{B. Active Devices}

Discretes: A surprising observation has been that certain off-the-shelf discrete transistors, i.e., commercially packaged silicon JFET's, display changes in characteristics from 25$300^{\circ} \mathrm{C}$ that are small enough and of an appropriate nature so that these JFET's function usefully in geothermal circuitry. The temperature characteristic of these JFET's was first determined experimentally and subsequently verified by detailed computer analyses [7]. The JFET's were stable at $325^{\circ} \mathrm{C}$ for periods of 1000 hours. Silicon MOSFET's, on the other hand, were not stable at these temperatures, but were used reliably to $250^{\circ} \mathrm{C}$. Silicon bipolar transistors suffer from large leakage currents and they show thermal-runaway tendencies at $300^{\circ} \mathrm{C}$. Bipolar transistor use to $200^{\circ} \mathrm{C}$, and in specially designed circuits to $250^{\circ} \mathrm{C}$, is currently feasible. Junction diodes, though leaky, can be employed to $300^{\circ} \mathrm{C}$.

Computer studies not only confirmed the behavior of the JFET's, but also suggested several doping and dimensional design changes that should improve high-temperature performance. In addition, by comparing computer results with experimental data, it was found that most devices contained high concentrations of impurities that produced trap- 
ping sites in the band gap. One possible impurity is gold, which diffuses from the back of the devices; therefore a set of devices is presently being fabricated without gold backing to test this assumption.

Analysis of packaged transistors that failed in hightemperature tests has shown that the most common problem is bond breaking, which often occurs where the aluminum wire attaches to the package gold pad. Occasionally the chip lifts off the package pad. While these failures were bothersome in early development when printed circuit boards and packaged transistors were used, they are not encountered in the hybrid versions where unpackaged transistors are used.

A common problem with MOS devices is drift in characteristics during high-temperature exposure. The exact symptoms strongly suggest mobile ions in the oxide. While commercial production techniques attempt to minimize these contaminants, even more stringent care is apparently needed.

Both JFET's and MOSFET's display a point or region at which the drain current-gate voltage characteristic is substantially independent of temperature (Fig. 3). The geothermal circuits that were designed and tested in the laboratory and in the field use JFET's operating in this region.

Commercial gallium-arsenide devices are intended for high-frequency moderate temperature use. High-temperature characterization of the available GaAs MESFET's and JFET's revealed severe shortcomings. For example, the gold alloy metallizations currently used are unstable above $250^{\circ} \mathrm{C}$ showing both large-scale migration and phase change after testing. In addition, the MESFET's exhibited large gate-to-channel leakage at high-temperature due to the inherently low potential barrier at the metal-GaAs interface. One commercial JFET device had excessive surface leakage apparently due to passivation which was not suitable for high-temperature use.

Integrated Circuits: The complexity of many circuits demands the use of IC devices. Most silicon integration is accomplished using junction isolation between transistors. That is, the transistors that are to be isolated from each other are formed in doped wells that are reverse-biased from the substrate. With such isolation, IC's show excessive transistor interaction above $200^{\circ} \mathrm{C}$. IC's are also produced with dielectric isolation where the transistors are separated from each other by a dielectric barrier. A selection of radiation-tolerant IC's is constructed with dielectric isolation by several semiconductor manufacturers. Some of these circuits have been operated well above $200^{\circ} \mathrm{C}$ with useful characteristics (HA 2600 and HA 2520). Another way to isolate dielectrically is to fabricate the complete circuit on an insulating substrate. Commercial examples are CMOS IC's produced on a sapphire substrate (CMOS/SOS). Currently the selection of these devices is limited to large-scale memory devices and custom circuits.

In addition to inadequate isolation, there are other causes for high-temperature IC failure. Examples include the use of bipolar diodes for electrostatic protection in MOS IC's that become excessively leaky at high temperature, nonoptimum doping, inappropriate metallization and geometry, large surface trapping densities, and the presence of mobile ionic impurities. A series of small and medium-scale MOS IC's are

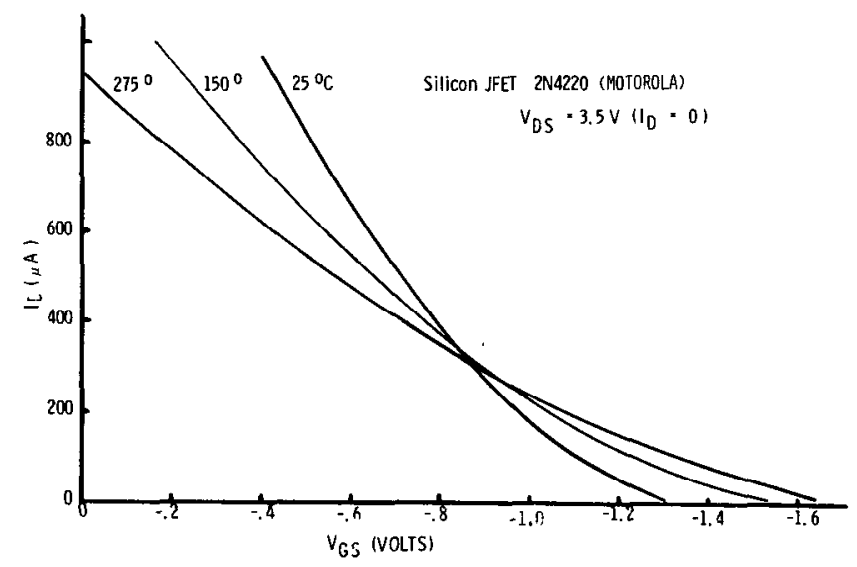

Fig. 3. Typical transfer characteristics measured with transistor in place in hybrid. Notice region of zero temperature coefficient of drain current near $-0.9 V_{G S}$.

now being fabricated at Sandia to study these issues in detail.

\section{Attachment and Packaging}

To fabricate high-temperatures, electronic circuits, special attachment, and packaging techniques are necessary. All materials used must, of course, have melting points above $300^{\circ} \mathrm{C}$. These materials must also have a hierarchy of melting temperatures that permits the desired sequence of assembly, i.e., substrate-to-package attachment, active device die-down, lid attachment. However, this hierarchy is not rigid since some attachment steps may involve only local or transient heating.

Packaging: Three techniques have been developed to attach the hybrid substrate (alumina) to the package. One uses a gold germanium solder (DuPont Formon paste 8513). The substrate back is prepared in advance with thick-film gold, and gold-plated packages are used. The eutectic melting temperature is $356^{\circ} \mathrm{C}$, but dissolution of gold from the parts raises the subsequent flow temperature substantially. A drawback of the method is that the eutectic tends to release flux in subsequent processing steps.

The second method uses a low-temperature sealing-glass thick-film (DuPont 8254). The substrate back is uncoated prior to attachment. The composition is thinly applied to both surfaces that are pressed together and dried for 24 hours at $100^{\circ} \mathrm{C}$. This schedule is appropriate for surfaces with $\mathrm{di}$ mensions of a few centimeters. The assembly is then fired at $500^{\circ} \mathrm{C}$ for $10 \mathrm{~min}$ using a belt furnace. A variation of the technique involves prefiring the glazed surfaces before assembly and final reflow. This variation permits the volitilization of contaminants that would otherwise be trapped [8].

The third method uses low-softening temperature silverglass compositions that are available commercially with silver contents from 20-50\% [9]. An appropriate composition can be selected to closely match the thermal expansion of the parts. After firing at $500^{\circ} \mathrm{C}$, a tenacious bond is formed. Each of these methods has been exposed to and has survived mechanical and thermal shock tests. Outgassing tests have not yet been completed. 
Die Attachment: Two techniques are used for transistor chip attachment. Those chips available in gold-beam lead format (such as BT4856 JFET and BZ821 Zener) are thermalcompression bonded gold-to-gold with a wobble bonder. Aluminum metallized devices with gold backing are scrubbed down to the substrate, that is held at $360^{\circ} \mathrm{C}$, while the tool is at $500^{\circ} \mathrm{C}$. A gold-silicon solution is formed during the process.

Parallel-gap welded gold ribbon is used to make electrical contacts between the hybrids and the package feedthroughs. It is also used to make certain transistor-to-hybrid and hybrid-to-hybrid connections.

Soldering: Package lids are attached with gold-germanium solder or preforms. Both alumina and gold-plated Kovar lids have been used. Generally large discrete capacitors, diodes, and thermistors are attached with gold-germanium solder onto polyimide PC boards with gold-plated copper lands. The hybrid packages are also interconnected to this PC mother board that is then mounted directly to the geothermal tool frame.

Chip and Wire: The previous steps of attachment and packaging have proved straightforward. Aluminum-wire bonding from silicon chips to thick-film circuits have been the exception [7]. The fundamental problem is the formation (moderate temperatures and times) of aluminum-gold compounds at the bond interface. Two approaches have been used to minimize this problem: first, modified fritless gold compositions were used to impede the intermetallic formation; second, diffusion barrier disks were affixed between the aluminum wire and the thick film.

Three commercial modified gold films were tested: DuPont 9910, AVX 3520, and TFS A328 (now designated 3028). All showed considerably less bond resistance increase and pull strength degradation with high-temperature aging than did pure gold fritless thick films (Figs. 4 and 5). Three wire alloys were also compared: pure aluminum, aluminum with $1 \%$ silicon, and aluminum with $1 \%$ magnesium (Figs. 6 and 7). Wire with $1 \%$ silicon proved superior for high-temperature operation. Aging tests from $250-350^{\circ} \mathrm{C}$ indicated that the same activation energy describes both the modified-and pure-gold film to aluminum-wire bond degradation. For geothermal instrumentation operated at $300^{\circ} \mathrm{C}$ for $1000 \mathrm{~h}$, any of these modified gold compositions would be acceptable. However, operation above $300^{\circ} \mathrm{C}$ would not be recommended for these directly bonded systems.

To reduce the degradation rate and thus achieve higher operational temperatures, special diffusion barriers were designed (see Fig. 8). These barriers are disks of Koval or nickel (1-mil thick, 30 mils in diameter) that have $1 \mu \mathrm{m}$ of aluminum deposited on one side and $1 \mu \mathrm{m}$ of gold on the other. The gold side is thermocompression bonded to the gold thick-film with a wobble bonder. The aluminum side received the aluminum wire from the transistor. No bond resistance change was noticed even with $350^{\circ} \mathrm{C}$ aging. The only bond strength degradation was due to annealing of the wire itself. Although this bonding method is far superior to direct aluminum wire to gold thick film, the circuits and environments encountered to date have not required this precaution.

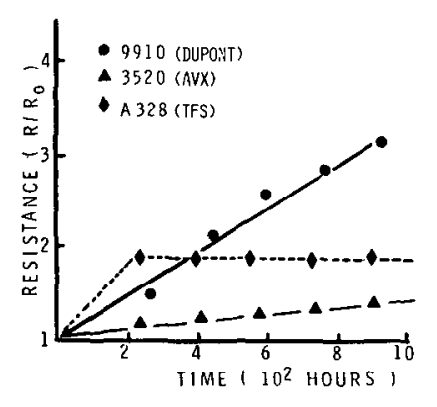

Fig. 4. Bond resistance versus time during $300^{\circ} \mathrm{C}$ aging. Fritless gold thick films are considered "plague-less" in normal circuitry. Initial bond resistance is typically $5 \mathrm{~m} \Omega . R_{0}$ is resistance prior to high temperature aging.

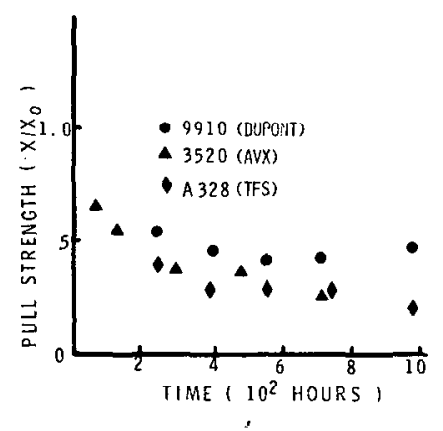

Fig. 5. Bond pull strength versus time during $300^{\circ} \mathrm{C}$ aging. Aluminum wire with $1 \%$ silicon was used. Initial decrease is due to wire annealling. Initial pull strengths are $8-12 \mathrm{~g}$. $X_{0}$ is pull strength prior to high-temperature aging.

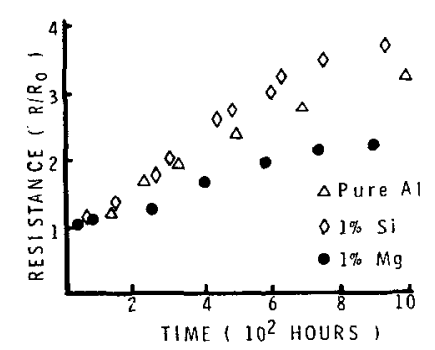

Fig. 6. Bond resistance versus time during $300^{\circ} \mathrm{C}$ aging for three wire alloys. DuPont 9910 is thick-film conductor. $R_{0}$ is resistance before high-temperature aging.

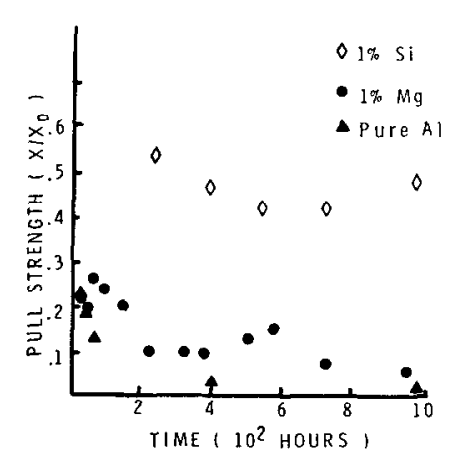

Fig. 7. Bond pull strength versus time during $300^{\circ} \mathrm{C}$ aging for three wire alloys. DuPont 9910 is thick-film conductor. $X_{0}$ is pull strength before high-temperature aging. 


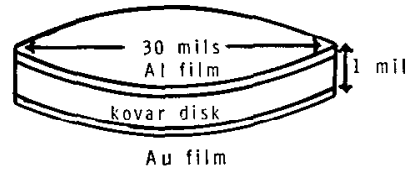

(a)

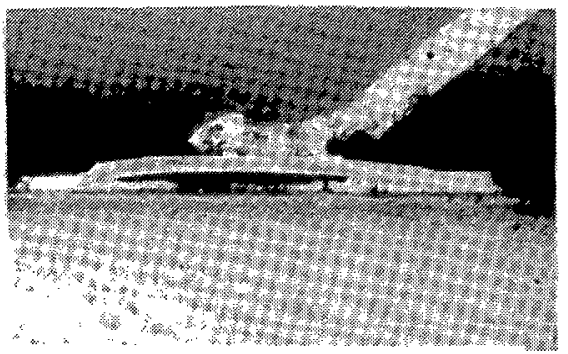

(b)

Fig. 8. Diffusion barrier pads. (a) Schematic of pad, Al and Au films are vacuum deposited. (b) Cross section micrograph of pad on thick film. Notice that pad is "buggcd" up from thermocompression attachment tool which presses on pad around edge deforming rim.

\section{Wire}

Therc are two applications for wire in high-temperature circuits: 1) windings on magnetic cores and 2) hookups between mother boards. To date, anodized aluminum wire has been used for windings [10], and Kapton (T.M., E.I. duPont de Nemours) or refractory-woven insulated nickel-plated copper wire [11],[12] has been used for other applications. Occasionally for short connections or discrete component leads, a glass braid has been placed over the bare ribbon or wire to prevent shorting. Neither is completely satisfactory, and a search for alternatives continues.

The aluminum wire has been used for windings because of its insulation integrity to $500^{\circ} \mathrm{C}$ and its availability in many gauges. However, it lacks flexibility and strength and is difficult to bond. For example, a standard toroid winder exerts enough flexure on the aluminum wire to break it. Also, interconnections made either by crimping or by spot welding the oxide-stripped wire to a nickel ribbon have been unreliable.

Most commercial insulations that will tolerate high temperature are bulky and available only in large sizes. Hi Temp Wire Inc., Boston Insulated Wire and Cable Company, and ITT produce types of stranded asbestos-glass-mica insulated wires that are functional to at least $450^{\circ} \mathrm{C}$. However, because of the insulation thickness, the smallest standard wire is 50 mils in diameter, much larger than convenient for windings or hookup. Certain Teflon (T.M., E.I. du Pont de Nemours) coated wire is advertised for operation to $300^{\circ} \mathrm{C}$, but the insulation is considerably softened at this temperature.

One wire being specially manufactured for high-temperature application for interboard hookup consists of 26 gauge solid nickel with a 0.004 in Kapton coating [11]. It has proven satisfactory at $300^{\circ} \mathrm{C}$ at low voltages. Long-term hightemperature aging and high-voltage tests have not been completed.

\section{E. Magnetic Materials}

High-temperature transformers were under development during the mid-1960's, but are not now available as standard commercial items [13]. Consequently, material evaluations and, conceivably, some development will be required to meet geothermal logging needs. At present only two magnetic materials are in current use in Sandia's geothermal logging instruments: a permanent magnet in the casing collar locater and a transformer core in the flow transducer. However, in order to implement more elaborate and diverse circuitry, other magnetic materials will be necessary. To date, only a very limited amount of work has been done. Briefly the results follow.

1) For permanent magnets, Alnico II, V, and VI are useful to at least $500^{\circ} \mathrm{C}[14]$.

2) $\mathrm{Fe}-\mathrm{Si}$ isotropic or grain oriented strip functions satisfactorily to $500^{\circ} \mathrm{C}$ [15]. Low-frequency losses, in fact, decrease by $60 \%$ between room temperature and $550^{\circ} \mathrm{C}$.

3) Simple $\mathrm{Ni}$ ferrites have been used to at least $250^{\circ} \mathrm{C}$ in standard transformers and inductors. Test results for several commercial ferrites are shown in Fig. 9. Their Curie temperatures are over $500^{\circ} \mathrm{C}$, and their permeabilities increase by about $20 \%$ from $0-300^{\circ} \mathrm{C}$.

4) In square-loop applications Li-ferrites have been operated to $300^{\circ} \mathrm{C} \mathrm{[16],[17].} \mathrm{The} \mathrm{permeability} \mathrm{doubles} \mathrm{from} 0$ $300^{\circ} \mathrm{C}$, and the Curie temperature is above $600^{\circ} \mathrm{C}$.

\section{CIRCUIT FABRICATION TECHNOLOGY}

The techniques used for circuit layout and fabrication will be illustrated by a particular high-temperature circuit (see Fig. 10(a)): a voltage regulator that is used in all of Sandia's fielded geothermal instruments [18]. It requires approximately $30 \mathrm{~V}$ at the cable head and produces a regulated $15 \mathrm{~V}$ output with $50 \mathrm{~dB}$ isolation from changes in the cable-head voltage. To enhance reliability it uses a minimum number of resistors, capacitors, and transistors.

\section{A. Layout}

Fig. 10(b) and (c) shows the mask design of the regulator. Four patterns are printed on one substrate that is subsequently divided into four substrates. Noticeable features are the large size of the details. For more standard applications, all components would fit comfortably on one small substrate. This enlargement was done because there is no pressing need for extensive miniaturization and because circuit yield was improved. Furthermore, when a part of the circuit was found defective, only that part need be replaced.

Particular novelties in the layout can be seen in the Fig. 10. Points $\mathbf{A}$ are oversized die-attachment pads. Since the active devices are electrically screened in place, it is common to die attach two chips so that if the first one connected does not function within specifications at high temperatures, the second can easily replace it. Several of the bonding pads (B) are also oversized to allow use of diffusion-barrier pads. Conductor islands, Points $\mathrm{C}$, allow transistor testing prior to commitment to the circuit. The gold bonding pads are large enough to accommodate both the aluminum wire and goldribbon leads. After the individual transistors are tested, the same gold ribbons are shortened and used as jumpers to connect the device into the circuit. The large rectangular shapes (D) are resistors made in this configuration because high-tem- 


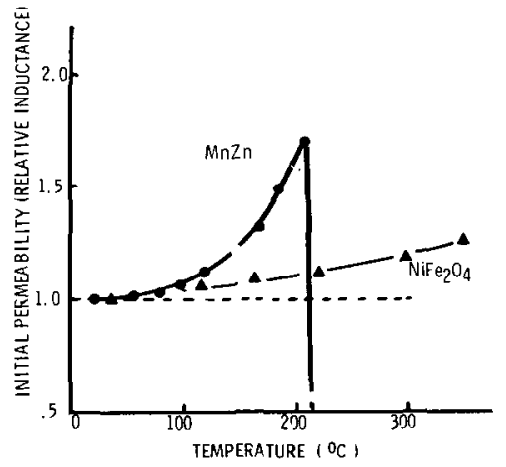

Fig. 9. Permeability versus temperature of common ferrites. Measurement of inductance of sample at $10000 \mathrm{~Hz}$ was used. Dashed line represents air core inductor.

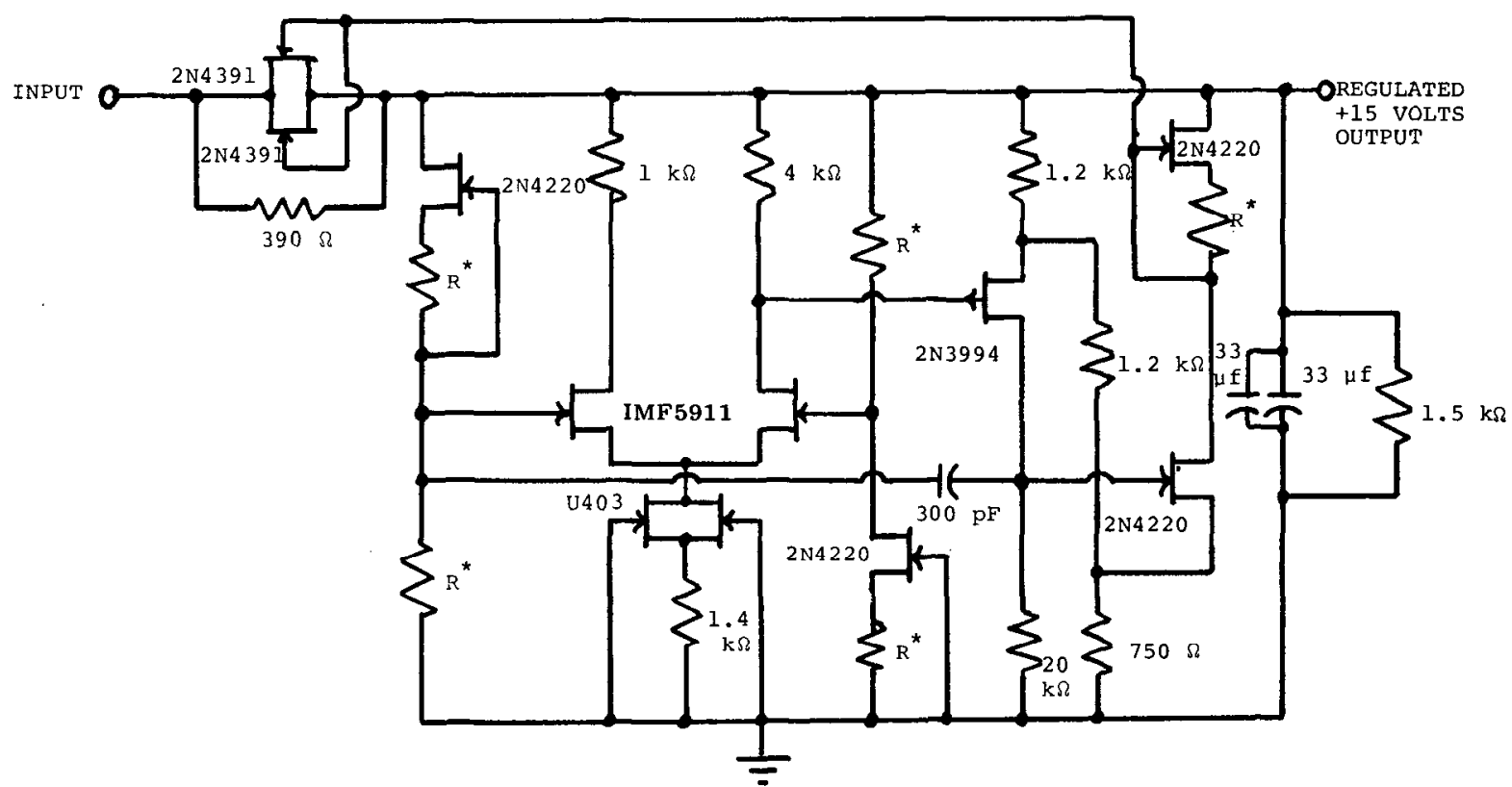

(a)

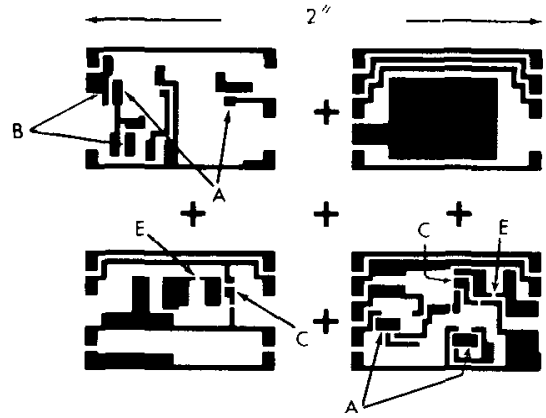

(b)

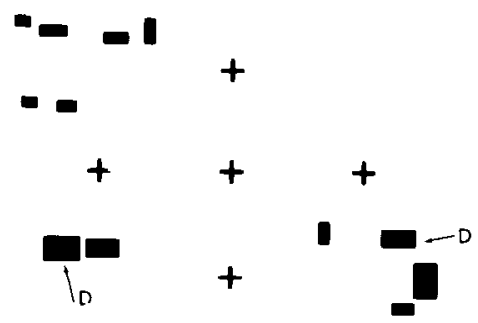

(c)

Fig. 10. Schematic of $25-300^{\circ} \mathrm{C}$ voltage regulator. (a) Resistors $\left(R^{*}\right)$ are trimmed after transistors have been characterized at 25 and $275^{\circ} \mathrm{C}$. Masks for voltage regulator circuit (enlarged). (b) Bottom conductor pattern. (c) Resistor pattern $(1 \mathrm{k} \Omega / 0$ ). (A) Large chip pads for redundant die down. (B) Large bonding areas to permit diffusion barrier attachment. (C) Isolated transistor pattern for device testing before commitment to circuit. (D) Large rectangular resistors for stability and case of trimming. (E) Shorting pads to allow bypass of one resistor of a pair in series if extremely large trimming is required. 
perature stability is enhanced and greater flexibility in laser trimming is achieved. For resistors that require adjustment over a large range, two patterns are used in series, one of which may be entirely shunted with a gold-ribbon bridging gap (E). Not shown in this circuit are capacitors with the top electrode sectioned to allow trimming.

\section{B. Materials}

For this circuit the following materials were used: DuPont 9910 fritless gold conductors, selected to eliminate aluminum and wire bond complications; ESL 4301 dielectric for capacitors, double printed and double fired to ameliorate the pinhole problem; Cermalloy 530 and 540 resistor inks, altered for high-temperature TCR compensation; and alumina substrates cut from a single piece on which all patterns were simultaneously printed.

Package-to-polyimide board attachments are made by passing the leads through the board to the underside and soldering. Electrical connection is made using gold-ribbon jumpers. This technique permits fairly casy replacement, even in the field.

\section{Circuits}

To date the following subcircuits have been designed and used: voltage regulators, comparators, line drivers, amplifiers, and pulse shapers. In turn, these modules have been used to make the following instruments: a temperature monitor with $0.02^{\circ} \mathrm{C}$ resolution and $0.3^{\circ} \mathrm{C}$ accuracy, a pressure monitor with 5 psi resolution at 5000 psi and \pm 20 psi accuracy, and a flowmeter capable of measuring propeller revolution rates from $0.1-10 \mathrm{kHz}$ with 1 part in 1000 of full-scale resolution.

\section{PERSPECTIVES AND DIRECTIONS}

In the following paragraphs we comment on and speculate about the near future of high-temperature electronics. It is a relatively new field largely unpublicized, so that these remarks may be useful to some readers. For basic technical reasons, the subject divides into two areas, electronics for approximately $300^{\circ} \mathrm{C}$ and below and for temperatures above $300^{\circ} \mathrm{C}$. Our discussion is organized accordingly.

\section{A. $300^{\circ} \mathrm{C}$ and Below}

The success to date in achieving useful circuits in this temperature range has rested on the fact that, by chance, substantial parts of the technology existed at the outset of the program and the major effort was in identifying what could be used and what could not. This reservoir has not yet been exhausted so that further rapid development is possible for the next few years. We expect that more silicon device types will become available that are stable at $300^{\circ} \mathrm{C}$. These devices will include MOSFETs. Major advances should be possible in integrated circuits using fabrication methods that provide stable high-temperature operation and adequate high-temperature device isolation. A wider range of high temperature capacitors, including thin-film components, appear practical. Progress can also be expected in the redevelopment of magnetic components, stable GaAs diodes, and the inclusion of bipolar transistors through appropriate and novel circuit design.
How far and how fast this technology is developed depends heavily on the number and type of uses and, of course, the attendant level of support. Four prominent industries are presently known to us to be actively interested in high-temperature electronics. The automobile industry is interested for engine control to improve fuel economy and reduce exhaust pollutants [19]. The well logging companies are interested for deep hot gas and geothermal well measurement tools. The jet engine industry and the military are concerned with engine performance monitoring [20], a task that is presently done by cooling the engine-control electronics with fuel. The electric power industry, including the nuclear reactor industry, is interested for power plant diagnostics and safety. In each application, an alternative to the use of high-temperature electronics would be to place the electronic package at a cool location and connect it to transducers with cables. However, noise pickup, signal transmission, and safety problems are often sufficiently bothersome so that some close-in amplification and processing is desirable or necessary. In fact, in nuclear reactors it is often forbidden to breach walls or containers with cables or transducers so that an internal self-contained monitor/broadcaster is useful.

The potential market within a few years is not insignificant. Our very rough estimates place it at between $\$ 100$ and $\$ 200$ million/year. The automobile industry provides the bulk of the volume, $\$ 100$ million/year, if one assumes 10 million cars/year, each requiring one \$10 IC. Well logging is more than a $\$ 1000000000$ business, about $10 \%$ of which is in logging deep hot gas wells. Logging of geothermal wells is negligible at present. About $10 \%$ of the logging cost is electronics. Hence these applications suggest about $\$ 10$ million/year in hightemperature electronics. The jet engine and power plant requirements have been much more difficult to estimate, but we believe that these applications may be between $\$ 1$ and $\$ 20 \mathrm{million} / \mathrm{year}$ each. These figures assume, for example, $\$ 10000$ per plane and 1000 planes per year, both military and civilian, and 1500 or more electric generating systems in the United States at $\$ 1000$ or more per year per system.

\section{B. Beyond $300^{\circ} \mathrm{C}$}

At higher temperatures silicon active devices will no longer suffice, and alternatives will be needed. These certainly include transistors using wider band gap materials (GaAs), hightemperature ceramic thermionic tubes, integrated thermionic circuits [21], and magnetic amplifiers. Some thick-film resistors have provided reasonably stable operation at $500^{\circ} \mathrm{C}$ as have a few single crystal and thin-film capacitors. However, the underlying problem of high-temperature material incompatibility persists and will complicate developments in all of these areas. There are no fundamental problems which seem to us to be insurmountable or that rely on substantial breakthroughs to develop the technology. The significant issue will be how compelling the need is.

A few applications can be identified. Geothermal wells have been recorded to at least $370^{\circ} \mathrm{C}$, and the impetus to find still higher temperature wells will be present in the long term. There is also active interest in drilling into magma $\left(1050^{\circ} \mathrm{C}+\right)$ for energy extraction. Electronic generating plants 
typically operate with $500^{\circ} \mathrm{C}$ steam with much higher temperatures in the vicinity of the combustion chambers or reactor cores. In sodium-cooled reactors, the liquid metal is kept near $500^{\circ} \mathrm{C}$. There are also those special applications, the Venus lander and solar flyby probe that might find uses for higher temperature electronics. To our knowledge, however, none of these areas has expressed an urgent near-term need for this technology.

\section{REFERENCES}

[1] V. K. Jonsson, "Geothermal power utilization," Alternative Energy Sources, J. P. Harnett, Ed. New York: Academic, 1976, Ch. 10, p. 296.

[2] N. R. Iammartino, Chemical Engineering, p. 79, Nov. 8, 1976.

[3] J. B. Coleman and J. P. Welsh, "The thermal design of hightemperature electronic parts and equipments," HF-1053-D-13, 1959.

[4] D. W. Palmer and G. L. Knauss, " $275^{\circ} \mathrm{C}$ microcircuitry: resistors, capacitors, conductors, substrates, and bonding," SAND760611 , available through NTIS.

[5] D. W. Palmer, "Hybrid microcircuitry for $300^{\circ} \mathrm{C}$ operation," IEEE Trans. on Parts, Hybrids, and Packaging, vol. 13, no. 3, p. 252, Sept. 1977.

[6] North American Philips, Mepco/Electra Distributors.

[7] D. W. Palmer et al., "Active devices for high-temperature micro- circuitry," SAND77-1145, available through NTIS. J. D. McBrayer, D. W. Palmer, C. R. Hickam, "Semiconductors and $300^{\circ} \mathrm{C}$ Hybrid Microcircuits," Proc. 1977 of the Int. Microelectronics Sym. Oct. 24-26, 1977, pp. 241-248.

[8] Private communication, Bill Brunstedt, Thick-Film Systems.

[9] Thick-Film Systems 3343, EMCA 92.

[10] Permaluster Inc.

[11] From Boston Insulated Wire \& Cable Co. (Bostrand Insulation).

[12] HiTemp Wire Inc. (Inorganic Tape-Saturated Glass Braid).

[13] P. E. Kueser, "Development and evaluation of magnetic and electrical materials capable of operating in the $800^{\circ}-1600^{\circ} \mathrm{F}$ temperature range," Quarterly Rep., NASA-CR-54354 to 60 , 1965-6 Westinghouse Electric Corp.

[14] C. Heck, Magnetic Materials and Their Applications, Crane, Russak \& Co., Inc., 1975, pp. 191, 193, 250.

[15] Heck, p. 364. Also [3].

[16] Heck, op.cit., p. 618.

[17] J. Smit, Magnetic Properties of Materials. New York: McGraw-Hill, 1971, p. 214, 227.

[18] K. R. White, "High temperature geothermal circuit design," SAND78-0784.

[19] N. Lindgren, "Semiconductors face the '80's," IEEE Spectrum, Oct. 1977, p. 42.

[20] Private Communication from P.H. Riley of Rolls-Royce Limited Aero Div., L. Palkuti of Naval Research Lab, and H. Bray of Endevco.

[21] J. B. McCormick et al., "A new electronic gain device for high temperature applications," Los Alamos Scientific Laboratory Rep. LA-6339-MS, July 1976.

\title{
$X$-Band High-Burnout Silicon-Schottky Mixer Diodes
}

\author{
YOGINDER ANAND, MEMBER, IEEE, ARISTOS CHRISTOU, AND HARRY DIETRICH
}

\begin{abstract}
The development of a highly reliable thermal-compression bonded $X$-band silicon-Schottky barrier diode is described. A highburnout diode capable of handling peak RF power of 10-14 watts $\left(\tau=1 \mu \mathrm{s}, 10^{3} \mathrm{~Hz}\right.$ ) with a noise figure of 6.5-7.0 dB (SSB) was successfully demonstrated. These diodes are more rugged than whisker type point contact and Schottky-barrier devices and exhibit two to three times higher burnout resistance to RF pulses than Schottkybarrier diodes manufactured today. For this reason, they are very suitable for high-power military radar systems and especially useful for medium-power systems where limiters are not used to protect the mixer diodes.
\end{abstract}

\section{INTRODUCTION}

$\mathbf{B}_{\mathrm{n}}^{\mathrm{U}}$ URNOUT of microwave mixer diodes is a continuing maintenance problem for almost all systems. Burnout is generally caused by large RF power reaching the diode either from other radar sets or from the radar set's own transmitter. These diodes usually exhibit deterioration in detection and

Manuscript received July 24, 1978; revised August 4, 1978. This work was supported by the Naval Electronics Systems Command under Contract N00173-77-C-0029.

Y. Anand is with Microwave Associates, Burlington, MA.

A. Christou and H. Dietrich are with the Naval Research Laboratory, Washington, DC 20375. conversion properties. Burnout is generally defined as either a $3 \mathrm{~dB}$ degradation in diode-noise figure at $30 \mathrm{MHz} \mathrm{IF}$ frequency or a catastrophic failure such as an open or short circuit.

Microwave mixer diodes designed for $X$-band and higher frequencies have a small active region and therefore limited in power handling capability. These diodes find many applications in high-power radar systems. The sensitive mixers are generally protected from any high-power reflected signals by gaseous or solid-state limiters. These limiters allow low-level incoming signals to reach the mixer diodes, but reflect unwanted high powers. However, RF pulses of 1-50 watts peak with pulsewidth varying from 1-10 ns are often incident on the mixer due to "turn on" behavior of the gaseous or solid-state limiters. Both peak power and pulsewidth are important. in diode failure [1], [2].

In radar systems, mixer diodes also encounter $\mathrm{CW}$ or $\mathrm{RF}$ pulses with pulsewidths greater than $100 \mathrm{rs}$. These pulses occur in low-to-medium power radar systems where protective limiter type devices are not used. In this case, direct pick-up by antennas either from friendly radars or enemy jamming may also be responsible for degrading the performance of radar-system mixer diodes. 